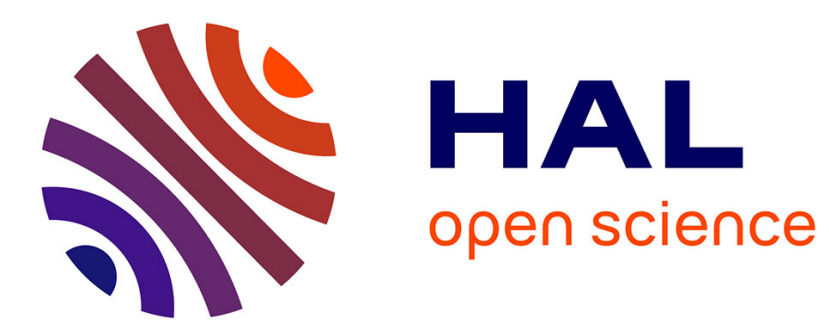

\title{
VAPOR-DEPOSITION AND MIGRATION OF IRON ON TUNGSTEN TIPS
}

\author{
Naoto Morikawa, T. Hara, F. Iwatsu, T. Terao
}

\section{To cite this version:}

Naoto Morikawa, T. Hara, F. Iwatsu, T. Terao. VAPOR-DEPOSITION AND MIGRATION OF IRON ON TUNGSTEN TIPS. Journal de Physique Colloques, 1989, 50 (C8), pp.C8-285-C8-290. 10.1051/jphyscol:1989848 . jpa-00229946

\section{HAL Id: jpa-00229946 https://hal.science/jpa-00229946}

Submitted on 1 Jan 1989

HAL is a multi-disciplinary open access archive for the deposit and dissemination of scientific research documents, whether they are published or not. The documents may come from teaching and research institutions in France or abroad, or from public or private research centers.
L'archive ouverte pluridisciplinaire HAL, est destinée au dépôt et à la diffusion de documents scientifiques de niveau recherche, publiés ou non, émanant des établissements d'enseignement et de recherche français ou étrangers, des laboratoires publics ou privés. 
COLLOQUE DE PHYSIQUE

Colloque C8, supplément au $n^{\circ} 11$, Tome 50, novembre 1989

VAPOR-DEPOSITION AND MIGRATION OF IRON ON TUNGSTEN TIPS

\author{
H. MORIKAWA, T. HARA, F. IWATSU and T. TERAO \\ Department of Materials Science and Engineering Nagoya Institute of \\ Technology Gokiso-cho, Showa-ku, Nagoya 466, Japan
}

\begin{abstract}
Field ion microscopic observation was carried out on iron films vapor-deposited onto a tungsten tip from the direction normal to the tip axis. Two kinds of experiments were performed: (i) iron was deposited onto a tip kept at cryogenic temperatures and then heated up to the temperatures $450-750 \mathrm{~K}$ and (ii) iron was deposited onto a tip at the same temperatures as in (i). The area of the deposited iron images was less than a half of the tip cap in the case (i) and more than a half in the case (ii), probably owing to the momentum carried by the deposited iron atoms.
\end{abstract}

\title{
1. Introduction.
}

The diffusion of iron atoms on a tip surface seems to greatly influence the growth and structure of vapor-deposited thin films. We already reported a study on vapor-deposition of iron onto tungsten tips at various temperatures $/ 1,2 /$. When the tip temperature during deposition was between $100-300^{\circ} \mathrm{C}$, an iron film epitaxially grew on one side of the tip. At the substrate temperature between $350-450^{\circ} \mathrm{C}$, the area of iron deposits spread over to the side on which the iron atoms did not impinge directly. This spreading of the iron area increased as the substrate temperature was raised. $\mathrm{At} 650^{\circ} \mathrm{C}$, we found an ordered arrangement of bright spots with a long periodicity. At this temperature, surface atoms of tungsten are reported to move along steps 13/. This long periodicity, therefore, was regarded as of a superlattice structure owing to the Fe-W alloy formation. When the tip temperature during the deposition of iron exceeded $700^{\circ} \mathrm{C}$, an iron image was not observed but an image of tungsten reconstructed from the field-evaporation end form. Recently, we studied the structure of iron films deposited onto tungsten tips kept at cryogenic temperatures from a direction normal to the tip axis (in preparation for publishing). When the tip temperature during deposition was kept at as 10 as $80 \mathrm{~K}$ or lower, an iron crystal was observed only on one side of the tip cap facing the evaporator. The obtained iron crystal contained many defects in it and its (110) step rings split into two or three on the surface. Although the position of the (110) step rings of the iron deposits displaced a little from that of tungsten substrate, the discrepancy decreased gradually as the iron was field-evaporated and they eventually coincided with each other. The two or three iron layers from the interface with tungsten took an almost epitaxial relationship with the substrate tungsten.

By means of heating of the above mentioned iron film which was deposited in advance on a tungsten tip at cryogenic temperatures, we expected to observe the surface diffusion and the rearragement of the iron atoms, (i). on the other hand, the deposition of iron onto a tungsten tip kept at the same temperatures as the above mentioned heat treatment was also carried out, (ii). The movements of the iron atoms on the tip surface in the case of (i) can be different from these in (ii) with the aid of the momentum carried by the vapor-deposited atoms.

\section{Experimental}

Iron was deposited in situ in an FIM on one side of a tip cap from a 
direction normal to a tip axis, Fig.1. The one side of the tip cap facing the evaporator will be called "the front side" and the other side "the back side", hereafter. Two series of experiments were carried out: (i) iron was first deposited onto a tungsten tip and then heated up to temperatures between $450 \mathrm{~K}$ and $750 \mathrm{~K}$, and (ii) iron was deposited onto a tip kept at the same temperatures as in the experiments (i).

The experimental conditions of the instrument were improved on the midway of the present study. we obtained, therefore, two kinds of data under the following conditions: (A) the vacuum, on the order of $10^{-7} \mathrm{~Pa}$, the tip temperature, $80 \mathrm{~K}$ and (B) $10^{-8} \mathrm{~Pa}$ and $45 \mathrm{~K}$. The FIM images of the iron deposits were usually observed with $\mathrm{H}_{2}+\mathrm{He}$ imaging gas in (A) and $\mathrm{Ne}$ in (B). The iron source was made of a pure iron wire $(99.99 \%, 0.5 \mathrm{~mm}$ dia.) and heated with an electric current passed directly through it. The source temperatures were in between 1400$1550 \mathrm{~K}$. The tip temperatures were measured by a four terminal method /4/. The details of the experiment will be published elsewhere.

\section{Results}

FIM images of iron films deposited onto tungsten tips under the conditions (A) $80 \mathrm{~K}$ (on the order of $10^{-7} \mathrm{~Pa}$ ) and (B) $45 \mathrm{~K}$ (on the order of $10^{-8} \mathrm{~Pa}$ ) are shown in $\mathrm{Fig} .2(\mathrm{~A}-\mathrm{a})$ and $2(\mathrm{~B}-\mathrm{a})$, respectively. Iron images are observed on one half of the screen corresponding to the front side. Heating those tips up to 450-750K for 3-5 minutes improved the crystallinity of the iron deposits. The area of the iron image gradualiy retreated from the apex along with the increase of the tip temperature as seen in the series of Figs.2(A) and 2(B). The iron deposits almost disappeared from the tip cap when the tip was heated up to $800 \mathrm{~K}$ or higher in either series, (A) and (B). The iron atoms may have the tendency to diffuse out of the tip cap to the shank area by the heat treatment. We did not realize any appreciable difference between these two series of the results.

on the contrary, the area of an iron image was more than a half of a tip cap when iron was vapor-deposited onto a tip kept at high temperatures, $450-$ $750 \mathrm{~K}$ as shown in Fig.3. The crystallinity of the iron films deposited onto tungsten tips kept at high temperatures (Fig.3) was of course much better than that deposited at cryogenic temperatures (Fig.2(A-a) and (B-a)). The iron area, however, did not spread with the temperature increase, contrary to our expectation. The advancement distance of the border of the iron area from the apex was not always the same and distributed in between 20 and $60 \mathrm{~A}$. The field-evaporation sequences from the images of Fig. $3(\mathrm{~A}-\mathrm{b})$ and 3 ( $B-\mathrm{b}$ ) are shown in Fig. 4. The iron images are observed on the back side on the periphery of the tip cap only in the case of the deposition under the better vacuum condition, as seen in Fig. $4(\mathrm{~A}-\mathrm{b})$ and $4(\mathrm{~A}-\mathrm{C})$. It should be noted that tha central area of the back side is free from iron atoms.

\section{Discussion}

The features of the iron image areas corresponding to the individual experimental condition are illustrated in Fig.5. The basic difference between the above two kinds of experiments (series (i) and (ii)) are the difference in the area of the iron image, the advancement of the border of the iron area to the back side or the retreatment from the apex. When an iron atom hits a tip surface, a part of its momentum carried from the evaporator is transfered to the substrate. The remaining momentum after the collision may contribute to the movement of the iron atoms crossing the tip cap. This is why the area of the iron image was wider in the case of the deposition onto a high temperature tip than that in the case of the heat treatment of the tip on which iron had been deposited in advance. The spreading distances of the iron image area in our previous study $/ 1 /$, on the other hand, gradually increased as increasing the substrate 

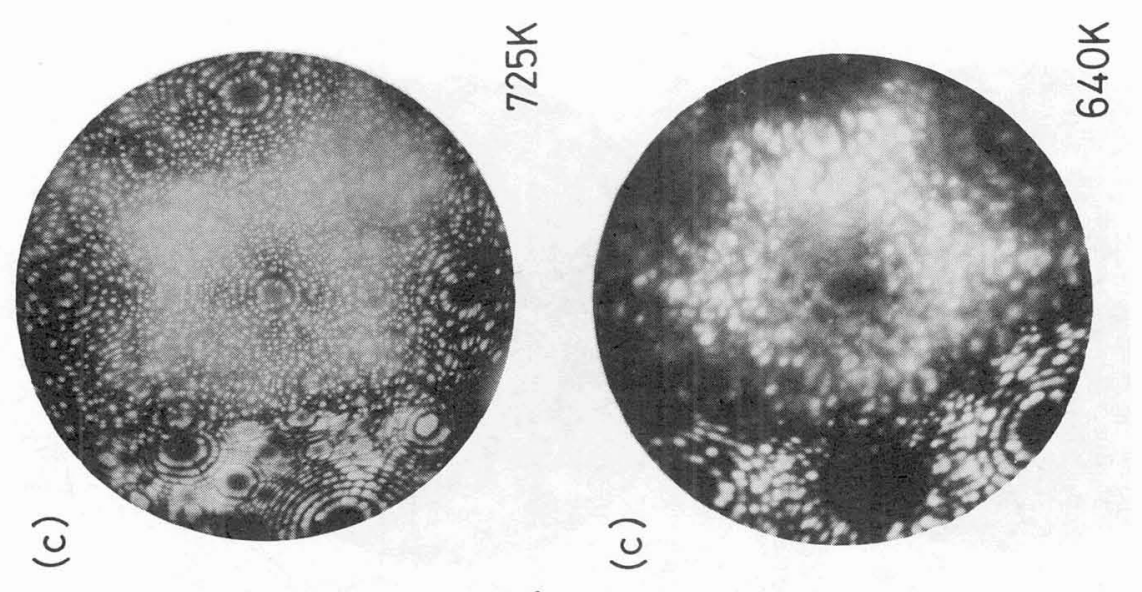

总

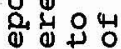

' 3

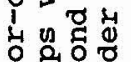

क्षे

\& 0

은

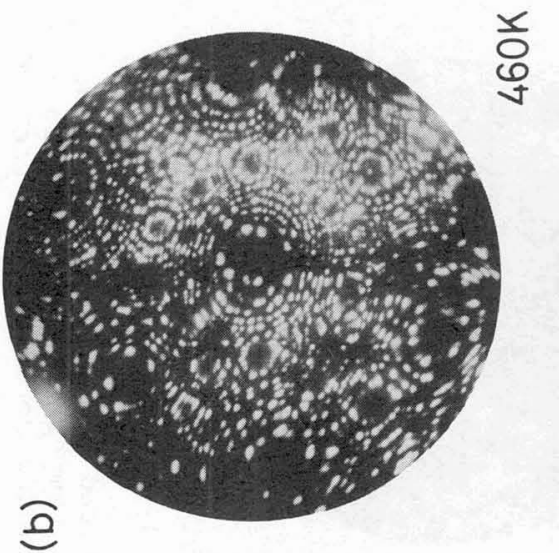

$x$
0
0

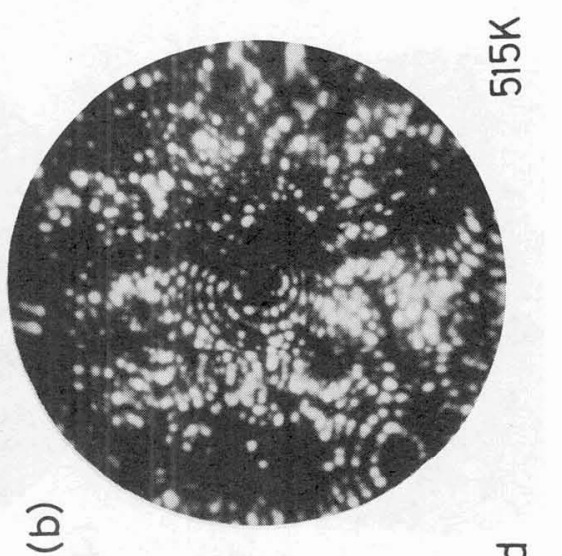

ㄷํ

近吉

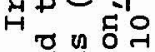

है

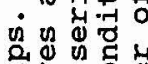

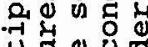

$+\rightrightarrows$ O

造究

$+5$

句爱.

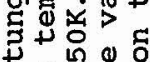

운

可古是

苟哥㝳品

궁든
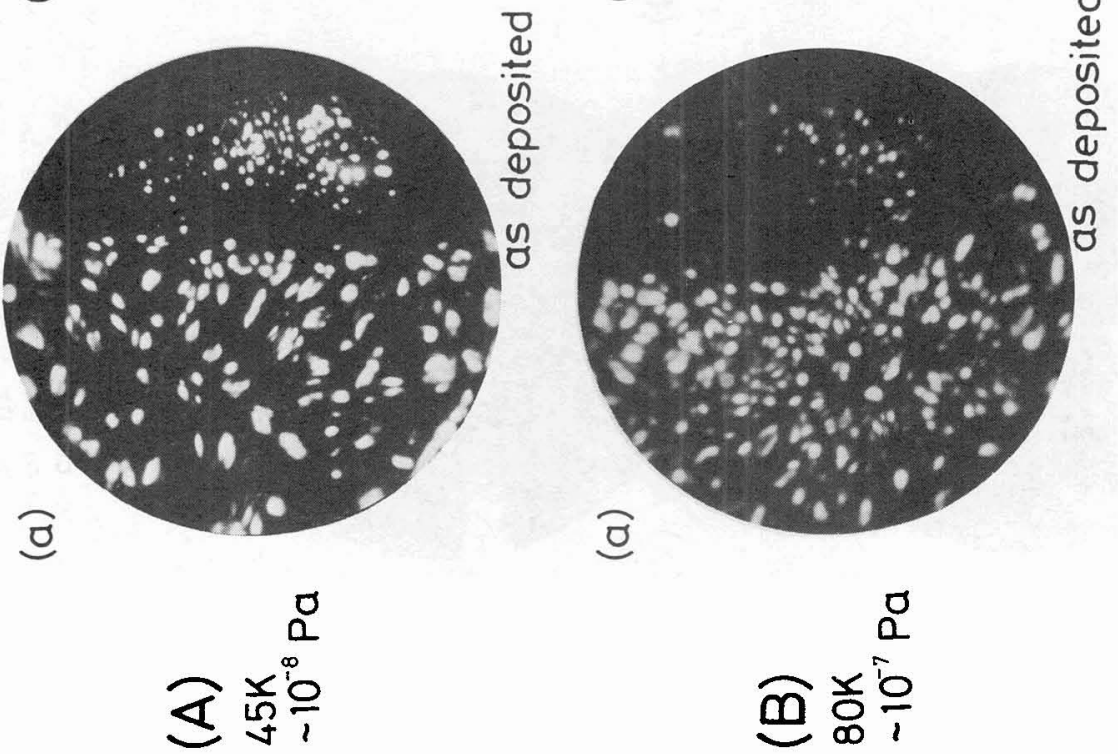

ه

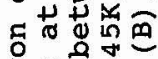

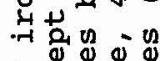

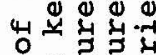

on

Q

\%+

.

$++\square$

员웅

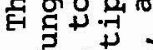

พ $0+000$

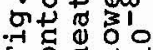

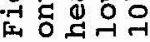

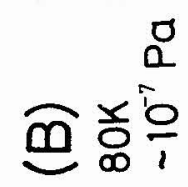



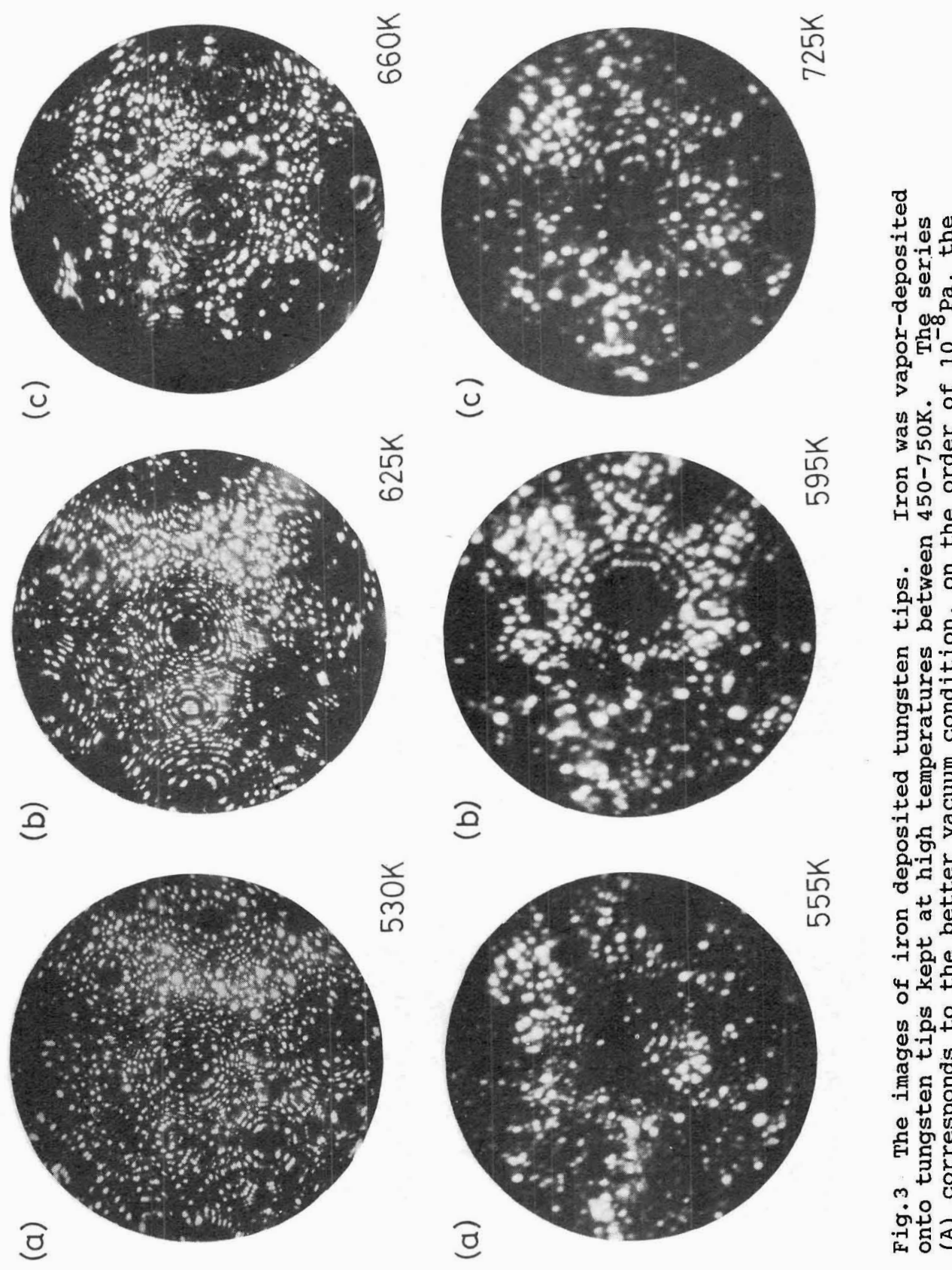

$$
\text { 近察운 }
$$

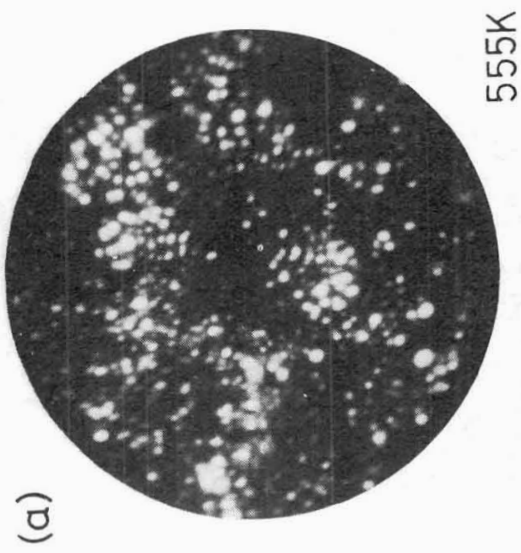

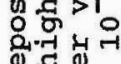
可势出 ธृ 出 न 0 व 山近

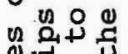
ont in 芦军 起苋勻 हु m $\begin{aligned} & 30 \\ & 0\end{aligned}$

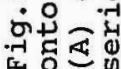

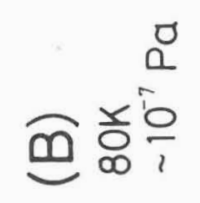



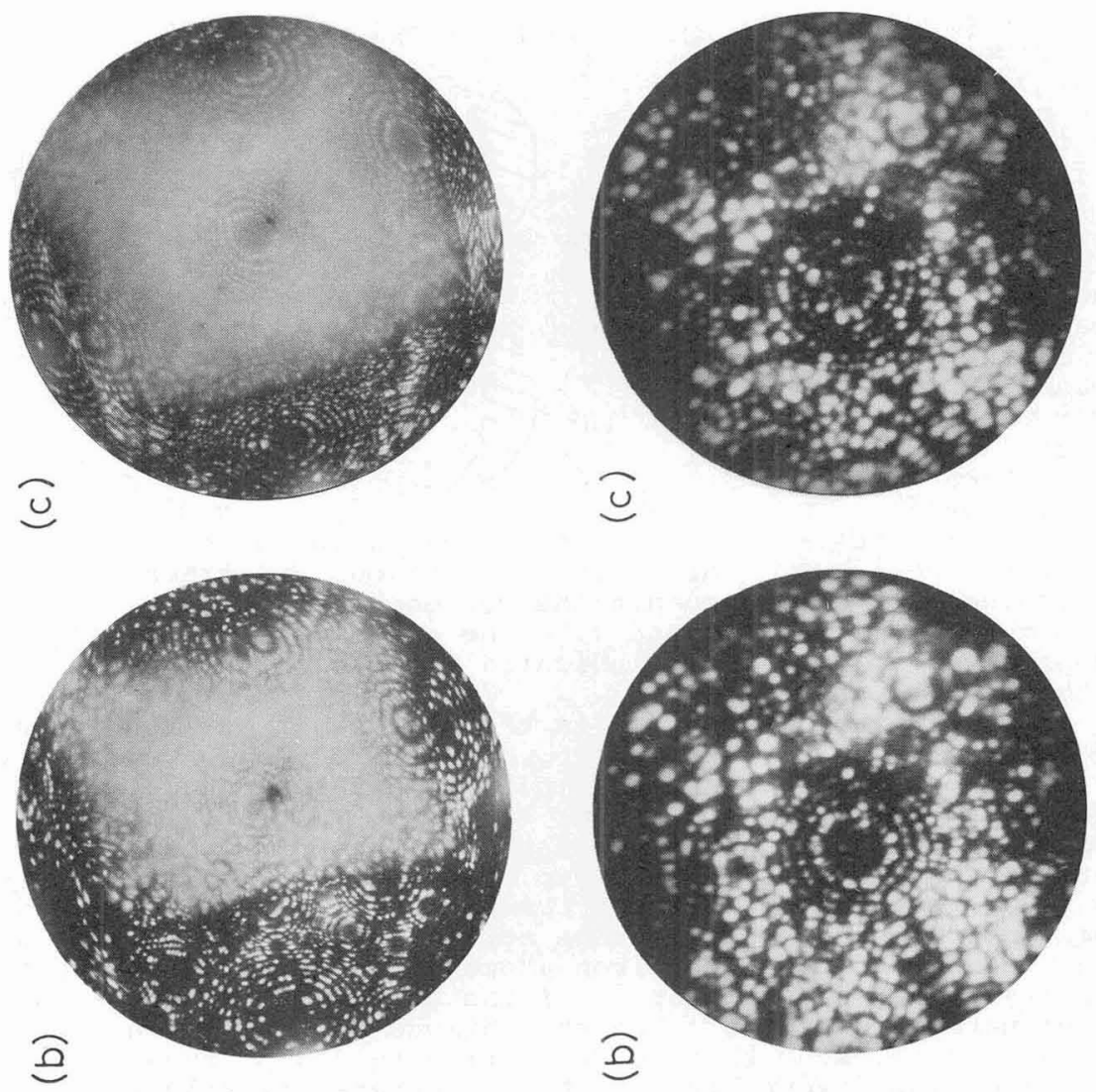

若 岂

量出

过

过 v

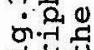

बन्त क्षे

[1

出

ข

㟔 동거

荧 $0 \pm$

- द्व

ฮ

봈

我政

on $?$

ขै है क्ष

ชั

एँ

踏

is
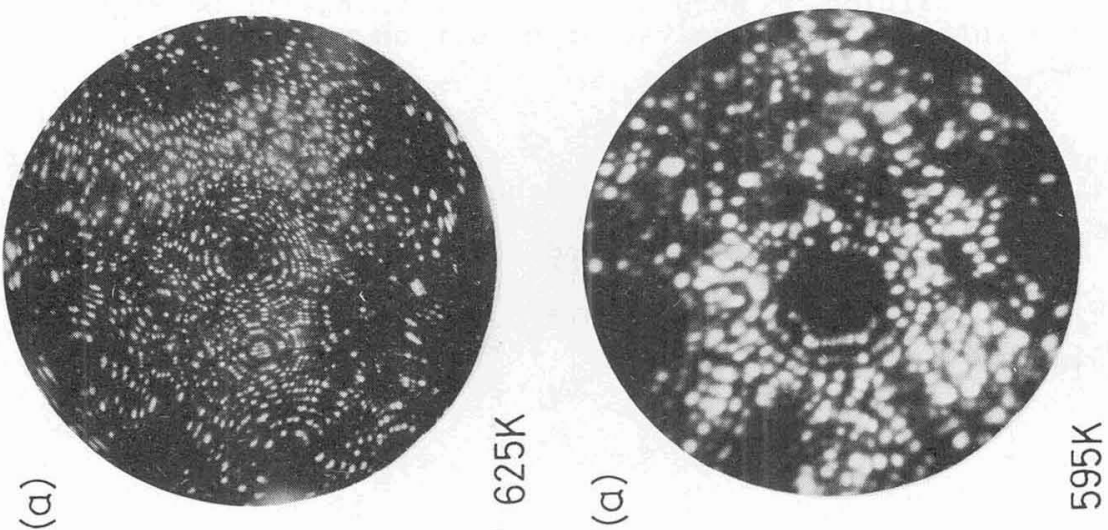

5

5

范

넝 동

त.

ए

1 $0^{0}$ u

욤

-1 40

ㅎํㅇ

ำ

嵌 ठิ

$$
\exists \stackrel{\substack{0 \\ \frac{0}{0}}}{\frac{0}{10}}
$$

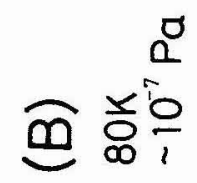


temperatures, and eventually the iron crystals covered the whole tip cap. The differences between the previous ones and the present ones are in the design of the evaporator and the vacuum conditions. The previous evaporator was a tungsten basket with the iron rod in it. The source temperature was possibly at around the melting point of iron and may be a little higher than those of the present case. The vacuum condition in the previous study was around $10^{-6}$ $\mathrm{Pa}$ which is poorer than that in the present study, around $10^{-8} \mathrm{~Pa}$. Either of these differences in experimental conditions could give rise to the difference between the present results and the previous ones. Another conspicuous variation among the results in Figs. 2, 3 and 4, as illustrated in Fig.5, is the appearance of iron image at the periphery of the back side of the tip cap. This iron image was observed only in the case of deposition onto a tip at high temperatures under the better vacuum condition, the order of $10^{-8} \mathrm{~Pa}, \mathrm{Fig} .4(\mathrm{~A}-\mathrm{b})$. This fact indicates that the movement of the iron atoms through the periphery of the tip cap is faster than that across the tip cap. comparing the images of Fig.4(A) and Fig.4(B), the movement through the periphery seems faster under the better vacuum conditions. The migration across the tip cap is also a measure of the surface diffusion of the iron atoms as well as the movement through the periphery is. The advancement of the border of the iron image area, however, have not showed so far such the obvious dependence on the vacuum conditions as the movement through the periphery did. These kinds of migration may depend on the orientations of the substrate crystals relative to the direction of deposition. More data accumulation will be required in order to detect the influences of the vacuum condition on the surface migration of atoms.

\section{References}

/1/ Morikawa, H., Suzuki, T., Terao, T. and Yashiro, Y, Surface Sci. 75 (1978) 538 .

/2/ Suzuki, T., shimizu, H., Morikawa, H. and Yashiro, Y., surface sci. $86(1979) 42$.

/3/ Bassett, D.W. and Parsley, M.J., J. Phys. D (AppI. Phys.) 3 (1970)707.

/4/ Morikawa, H., Kozakai, M., Terao, T. and Yashiro, Y., J. Vac. Sci. Technol. 21 (1982) 95. 